\title{
Research on the Planning Practice and Countermeasures of "Beautiful New Village" from the Regional Resource Integration
}

\author{
Niya Ma \\ Xi’an Peihua University, Xi’an, Shaanxi, 710125
}

Keywords: regional resource integration; industrial adjustment; development; Beautiful New Village

\begin{abstract}
Rural construction has always been an important construction direction in China. In the process of rural planning and construction, overall considerations need to be taken to examine the rural construction led by "Beautiful New Village". The transformation of rural areas means that the development of modernization has a very good effect on the transformation of rural areas and is an important part of China's development. Through the development of the "Beautiful New Village," village resources will be integrated and the key features of village will be given into play. At present, it is mainly focused on rural construction to increase rural development patterns and plan overall rural development measures. "Beautiful New Village” mainly adopts targeted research methods to study the interior and exterior of rural areas. Through the development status and a series of problems in development, this paper identifies important methods suitable for rural development and proposes important measures that are suitable for rural development. The overall analysis of the "Beautiful New Village" industry and transportation, etc., and its characteristic agriculture and industry will be made as an important development goal. Through the adaptation to local conditions and the direction of development of modern agriculture, this paper proposes a method of structural adjustment of the agricultural industry. Through strategic planning, the development of "Beautiful New Village" will be accelerated under the background of regional resource integration.
\end{abstract}

\section{Introduction}

Accelerating village construction and transforming modern villages are of great significance to the development of the village. The development of the beautiful village is a relatively important construction plan put forward by the country. For the problem of rural development, a beautiful village action plan has been formulated. In the implementation of the plan, it is necessary to focus on the development of the village and the environment, and to evade the old problems in the mahjong countryside that are not conducive to development. Taking the planning and construction as an important goal, the urban system will be applied to rural construction to create and nurture the industries in the region. In the vast countryside, the environment is beautiful, the water quality is clear, the terrain is complex, customs are preserved, and through the overall planning, the heritage of its cultural heritage is emphasized, and the landscape and style of the village are presented to the public. Planning of rural buildings will create distinctive rural buildings, disseminate native culture, optimize local economy, shape the image of the building, increase the income of rural residents, and create special advantages for the outdoor environment. Advocate away from the bustling city, take a breath of fresh air and discover the beauty of nature. From the long-term goal of planning, the construction of rural areas needs to start from the grass-roots level, taking the rural economy as a key factor for consideration. If the rural economy is to be developed and the income of the villagers increased, the rural economy can be reformed through the development of the tourism industry and be beautiful. The construction of villages has become a region with local cultural feelings. It combines its cultural characteristics with the region, preserves the surviving features, and adds new elements. According to the current construction of villages, reasonable planning and utilization of resource integration are proposed. It is of great significance to the development of society. 


\section{Overview of New Village Development}

This article is based on the research of Moon Bridge Village, Tianmushan Township, Lin'an District, Hangzhou City. Moon Bridge Village is located in the northwest of Zhejiang Province, about 70 kilometers from Hangzhou. It is one of the Qiantang River water systems, the birthplace of Tianmu Stream, and is located here. Outstanding and beautiful, it depends on Tianmu Mountain, the mountains and the water are integrated, and the landscape is beautiful. In recent years, relying on the advantages of culture and tourism, we have integrated resources and conducted a large number of explorations and experiments. We have tried to honor the country's beautiful townships.

Moon Bridge Village has 246 square meters, 408 villagers groups, the total population of 34,030 people. After 2014, the industrial sales value of 4.875 billion yuan, of which 1.453 billion yuan for industrial sale of property, 640 million yuan in agricultural output, more than 387 million in output value of the service industry, farmers The income is also greatly increased. The unique forest resources of Tianmu Town are rated as national forest protection areas. At present, there are more than 300 farmhouses in the town, and more than 1000 acres of Hangzhou-level food functional areas provide bamboo shoots, as well as stupid chickens, meat rabbits, and small fragrant mushrooms. Potatoes, peanuts, and so on, in the industrial sector, persisted in attracting investment and formed leading industries such as agricultural product processing. There are also many developments in the fruit industry, such as characteristic peaches and grapes. The current development of bamboo shoots is also relatively large and the industry is relatively concentrated.

The current building of Moon Bridge Village is mainly constructed by rural villagers. The style difference between the village and the building is relatively large. In the process of construction, some of them are old houses of villagers' buildings, and the colors are relatively leaping, and there are also some architectural differences. Bigger, the entire building complex is rather messy. There are also a number of villagers who build a lot of sheds everywhere and deal with this situation in a serious or poor health situation in a timely manner.

\section{The Status Quo of Rural Development}

For the development of rural culture is relatively slow, first of all as a rural villagers, their level of education is not high, highly-educated talent is seriously inadequate, in the industrial structure is still the traditional planting and aquaculture. There are also many workers who go out to work and resources cannot be optimized. However, although there are rich material and cultural resources in the countryside, in the face of abundant resources, due to the lack of reasonable allocation, the tourism resources have not been well developed, which has a negative effect on the development of the rural areas.

For the development of the countryside, the agricultural structure needs to be changed and the overall planning must be carried out. From ancient times to the present, the development of the villagers was mainly based on agriculture. The living environment of the residents was relatively scattered. Although the land for farming was relatively large, there was no centralized planning and construction. The aspect is also patchy, the color difference is relatively large and looks disorganized, and the overall style design is inconsistent with the entire rural development plan. Many traditional buildings are not protected.

The development of the countryside cannot be separated from the unified planning. From unified management to unified public land, coordinated development is required. From public areas to public facilities. The application of supporting facilities will be increased, and some unreasonable layouts will be planned in a unified way. Through good natural conditions, the advantages of the village will be fully utilized to develop the characteristics of the village and provide opportunities for rural tourism.

\section{The Adjustment of Rural Agricultural Resources}

The development of rural agriculture requires good structural adjustment of agricultural 
development. Adhering to ecological development is an important factor in optimizing the industrial structure. The development of the farming industry has occupied a major position since the ancient times. The planting industry has developed in many ways, intensively cultivating, changing the production structure of the monotonous production of grain, and will produce according to the needs of the market, replacing the grain crops with coarse grain crops. Plan production. The planting structure is adjusted. In the traditional agricultural development, many feeds come from the production of grain, but the agriculturalization is changed, the feed is obtained from the already-cultivated economic crops, and the agriculture, forestry, animal husbandry, and fishery are organically combined. The development direction of agriculture should extend from wanting development to vertical development, deepening the development of the industrial chain, industrializing the agricultural industry, cooperating with commerce, expanding the trade to the outside world, realizing deep processing of agriculture, raising agricultural output value, and increasing farmers' income. Because different villages have different economic conditions, in the development of the countryside, industry needs assistance, and the overall advantages of the village are judged according to the village's own conditions and development direction. The traditional rural construction mainly stays on the basis of technology and choice of samples, resulting in a relatively low price of the product, mainly because the main goods traded are raw materials, which seriously affects the development of the village. For villages with certain conditions, rural industry can be developed through the advantages of the village.

The development of rural agriculture has always been in the development of traditional agriculture. The structure of agricultural industry is relatively simple and the layout is irrational. The transformation of rural agriculture to modern agriculture is very important. It combines high-quality agricultural products with the concept of ecological development. Ecological technology and agricultural tourism are taken as part of rural development. Based on the local ecological environment, urban development will be achieved. The required agricultural products are finely planted, standardized and tested, and the output of high-quality agricultural products is strictly in accordance with the requirements. The ecological economy of rural agriculture will be upgraded to a grade. At the same time, we can use the functions of eco-agriculture to develop ecologically cycled agriculture, carry out soilless cultivation, save the use of resources, reprocess waste, re-filter and reuse, and develop agricultural recycling plants for efficient development. The role. The ecological tourism will be vigorously developed, the planting varieties and planting techniques will be improved, the advanced technology will be used to promote agriculture, the agricultural sightseeing tourism will be used as an economic income for the development of the rural economy, and the relationship between agriculture and natural ecology will be extended. Combine the production of agriculture with the development of agriculture and provide urban residents with a place for rural tourism.

For the development of rural agriculture, it is necessary to combine with industry to increase productivity. Due to the geographical environment of Moon Bridge Village, the cultivation of the village is not only food crops, but also many economic crops. The use of bamboo shoots, bamboo shoots, and vegetables as the best-selling industries in the market can be developed into a base for planting. Based on productivity, good bamboo and bamboo shoots and fruit can be used as the planting base, and leading industries can be developed. To speed up the cultivation of fruits, the form of farmhouse music can be incorporated into the harvest of seasonal fruits. At present, Moon Bridge Village has been built into a large bamboo shoot base, which will be used for large-scale cultivation of bamboo shoots to improve the environment. At the same time, small sweet potatoes and some coarse grains are planted in large areas of Laoshan, and reasonable planning for special industries is carried out. This environment also plays an important role in the development of ecological livestock husbandry. Lunar Bridge Village is rich in water resources and suitable for breeding rabbits and stupid chickens. However, aquaculture needs to be moderate and cannot contaminate water resources. Therefore, it is possible to choose a place that is far from the village for centralized breeding. 


\section{Research on Planning Practice in Rural Areas}

With the integration of regional resources and the implementation of the "Beautiful Village" policy, the attractiveness of Moon Bridge Village has gradually increased. The convenience of transportation has a very important role to play in the development of the countryside. At the beginning of the planning, the transportation needs to be comprehensively combed and planned. For the development of the village, it is necessary to maintain the original ecological features of the village itself, dismantle some illegal buildings, reconstruct the buildings of the village, and repair some buildings with cultural and historical features, and show the overall village through the overall collocation. Features. In the process of construction, it is necessary to coordinate development with the environment and give top priority to the ecological environment. The requirements for post-construction facilities have been further strengthened and improved, and the specific requirements of some rural residents have been considered overall. The key plan for the overall development and tourism development of Moon Bridge Village will be made.

Planning for the development of "beautiful villages" requires that the level of rural living requires the development of the economy, and the development of the economy needs to ensure the life of rural residents. There are abundant natural resources in rural areas and the rational exploitation of natural resources is an important goal to ensure the economic development of rural areas. With the development of the rural economy, the ecological system is well coordinated. This coordination ability can help the stable development of the rural ecology, and the development needs of the social economy will affect the rural economy. There are many phenomena of unbalanced economic development in the resources for rural construction. By looking for new growth points and the development of the rural economy, attention is paid to the development of the rural economy.

Integrate the tourism resources of Moon Bridge Village, excavate the rich natural resources of the local villages, pass on the cultural spirit in the countryside, and integrate the experience of nature and the rich ideas into the construction of the countryside. In the development of the natural environment, the terraces and the Tianmu River in the villages play their respective roles. The main landscapes are primitive forests, rivers, sand dams, etc. These projects mainly involve the development of water resources because there is abundant groundwater. While protecting, the original features of the landscape will be developed and will use its ecological and natural environment to attract the development of tourism. In the integration process of tourism resources, not only the development of the original landform attracts tourists. There are also many village developments and reservations of traditional consciousness, which will include local features of folk culture and customs. From the development of the village to the characteristic culture, giving tourists different experiences and integrating rural tourism resources will be conducive to the sustainable development of the rural economy.

\section{Rural Transformation Planning and Countermeasures}

When planning rural areas, it is necessary to pay attention to the development of tourism resources and combine the mountains, water, forests, and farmland of Moon Bridge Village to create a living space with a unique environment, and to use landscape as a background to increase the overall sense of experience and plan the space. The layout will be unified with the landscape, and the concept of an idyllic village will be introduced to present the project of production, ecotourism, sightseeing and tourism development. It will use the beautiful environment and pleasant climate to perceive the local material cultural heritage. It is inherited with local customs.

For access to villages for tourism, especially in the process of transportation planning, the rivers and roads must be characterized by green plants, greening areas should be increased, green belts should be formed, and both sides of the roads and parks should be planted with distinctive villages. Plants will be greened in the open space of the countryside, and the interior of the village will be built in courtyard style. The combination of fruit cultivation and greening will form an interesting pastoral scenery. At the same time, it can also provide rural tourism projects such as farm picking. 


\section{Conclusion}

With the development of society, the planning policy of "Beautiful New Village" has been continuously implemented. In the planning of rural areas, the combination of rich natural landscape and tourism development has changed the traditional structure of agricultural development and will be conducive to the development of rural areas. The rural economy has also greatly improved. For the integration of regional resources, from agriculture development to agricultural tourism and the development of tourism, the rural economy has greatly improved.

\section{References}

[1] Ye H. Research on the planning system of villages in the Pearl River Delta [D]. South China University of Technology, 2015.

[2] Cai Zhouyue. Research on Village Ecological Renewal Planning and Strategies during the Transformation Period in Developed Regions [D]. Zhejiang University, 2016.

[3] Zhou You. Research on the Construction of Guangdong Rural Planning System Framework [D]. South China University of Technology, 2016.

[4] Xin Guixin. Study on the Mechanism of Land Resource Flow and Integration in Hilly Region[D]. Southwest University, 2016.

[5] Peng Feng. Study on the planning of beautiful rural villages under the background of precision poverty alleviation[D]. Chongqing University, 2016.

[6] Wang Zhangjie. Research on the planning and design of beautiful rural boutique lines[D]. Zhejiang Agriculture and Forestry University, 2014.

[7] Du Zhuozheng. Study on the Construction of Beautiful Rural Area Based on Overall Governance [D]. Hebei Normal University, 2017.

[8] Li Jinfeng, Shi Shuxia. Study on Tourism and Poverty Alleviation and Development of Special Towns and Surroundings around Lanzhou City in the Perspective of Global Tourism[J]. Journal of Lanzhou University of Arts and Science (Social Sciences Edition), 2018, 01:65-72.

[9] Huang Zhenfang, Huang Rui. Research on Rural Culture in the Context of Urbanization and Tourism Development: Academic Contention and Research Direction [J]. Geographical Research, 2018, 02: 233-249.

[10] Yang Xiaojun, Fang Chuanshan, Hou Ye. Ecological Recreation Based on the Optimization of Urban Ecological Recreation Space in Xi'an[J]. Geographical Research, 2018, 02:281-291.

[11] You Zuyong. Opportunity, mission and responsibility of county in advanced urbanization stage[J]. Contemporary County Economy, 2018, 03:20-25. 